\title{
Towards the combination of automated lay-up and stamp forming for consolidation of tailored composite components.
}

\author{
T.K. Slange ${ }^{\mathrm{a}, \mathrm{b}}$, W.J.B. Grouve $\mathrm{a}^{\mathrm{a}, *}$, L.L. Warnet ${ }^{\mathrm{a}}, \mathrm{S}$. Wijskamp ${ }^{\mathrm{b}}$, R. Akkerman ${ }^{\mathrm{a}, \mathrm{b}}$ \\ ${ }^{a}$ Department of Mechanics of Solids, Surfaces and Systems (MS3), University of Twente, P.O. box 217, \\ 7500 AE Enschede, The Netherlands \\ ${ }^{b}$ ThermoPlastic composites Research Center (TPRC), P.O. box 770, 7500 AT Enschede, The Netherlands
}

\begin{abstract}
A process route is proposed where automated lay-up is followed by stamp forming for the manufacturing of load carrying components of thermoplastic composite. The focus is on rapid lay-up, rather than in-situ consolidation, while the final consolidation quality and shape are achieved by stamp forming. An experimental study offers improved understanding of the relation between blank preconsolidation quality and final quality and the role of the prepreg. Two C/PEEK prepregs are processed into blanks by ATL and AFP and subsequently stamp formed. The consolidation quality of the stamped blanks was characterized by C-scans, micrographs and density measurements, while the mechanical performance was evaluated based on flexural tests. The results demonstrate the key role of the prepreg, especially thickness variations, in the consolidation process, but also that high quality laminates can be obtained.
\end{abstract}

Keywords: B. Porosity, E. Automated fiber placement (AFP), E. Consolidation, E.

Forming

\section{Introduction}

Thermoplastic composites are increasingly being used in industry due to their advantages over thermoset composites. These advantages include a higher toughness, recyclability and potential for automated high volume manufacturing due to their weldability and formability.

\footnotetext{
*Corresponding author

Email address: w.j.b.grouve@utwente.nl (W.J.B. Grouve)

Preprint submitted to Composites Part A: Applied Science and Manufacturing
}

February 14, 2019 
5 The development of new lay-up technologies, such as automated tape laying (ATL) and automated fiber placement (AFP), over the past decades has provided new opportunities for the rapid manufacturing of large and complex components.

One of the benefits of automated lay-up is the possibility for highly automated manufacturing of blanks with a high degree of lay-up freedom. This enables the use of tailored lay-ups, which can be optimized for their final application in terms of local thickness and fiber orientations, allowing for more efficient material use and weight reduction compared to traditional lay-ups of uniform thickness. Moreover, near net-shaped lay-ups can be produced, which reduces scrap generated by trimming operations.

The current research and development efforts for automated lay-up mainly focus on material and process optimization to allow in-situ consolidation [1/7], where no expensive post-consolidation step is required after lay-up. Potentially, this is a very attractive manufacturing route; especially for larger, relatively simple, aerostructures, such as fuselage or wing skin sections. However, achieving in-situ consolidation still is a major challenge, especially at economically attractive lay-up rates. This is mainly due to the high heating and cooling rates and low pressure during the process, which provide very little time for consolidation phenomena like void elimination and development of interlaminar bonding. Most industrial applications therefore still rely on a post-consolidation step, such as press, autoclave or vacuum-bag-only consolidation, which are time and energy consuming processes.

As an alternative, automated lay-up could also be attractive for smaller and geometrically more complex parts. Here, however, the authors propose to focus on a two-step approach. Rather than aiming for in-situ consolidation, lay-up is performed at high rate, providing limited degree of consolidation. A subsequent, preferably quick and inexpensive, consolidation step has to be applied to achieve the final consolidation quality. Stamp forming may serve as an interesting alternative to conventional post-consolidation processes. Stamp forming uses the formability of thermoplastic composites at elevated temperatures to shape a flat laminate, a so-called blank, into a complex thin-walled three dimensional component. The blank is subjected to high heating rates in an IR oven in order to melt it, then quickly transported to a press, where the blank is quench-cooled by the isothermal 


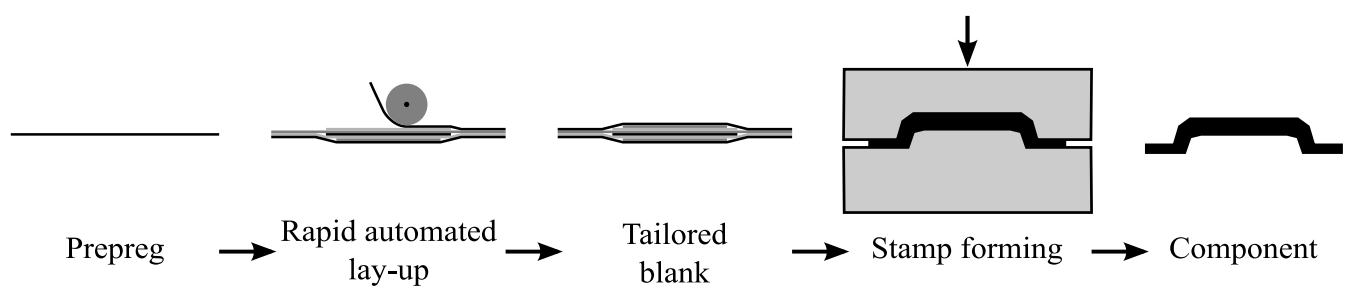

Figure 1: The proposed process route, combining rapid automated lay-up and stamp forming for the manufacturing of components with tailored lay-ups.

tooling during the forming process. Short cycle times can be achieved, especially compared to press consolidation, where the tool is heated to the processing temperature and cooled down again during each cycle. The short cycle times make the stamp forming process very attractive for series production and competitive to metal solutions. Despite the relatively short cycle times, stamp forming provides much more time, in the order of $5-20$ seconds, for consolidation phenomena to occur compared to an automated lay-up process, where the available time is typically less than 1 second. This potentially allows for the use of blanks which are not fully preconsolidated prior to stamping, hence enabling higher lay-up rates compared to lay-up with in-situ consolidation.

The proposed process route, combining rapid automated lay-up and stamp forming as illustrated in Fig. 1, benefits from the high rate lay-up of flat blanks with a tailored lay-up and near net shape contour, while still achieving high consolidation quality and a complex geometry after stamping. For these reasons, the proposed process route may have the potential for a step forward in the rapid manufacturing of load carrying components.

Despite the potential of this process route, the two processes allow little time for consolidation and the feasibility of the route is yet to be proven. Previous work has shown promising results on both consolidation quality and mechanical performance after stamp forming blanks produced by AFP and ultrasonic welding [8-11], as well as unconsolidated commingled yarn preforms [12, 13]. However, the achieved consolidation quality and performance were below that of conventionally consolidated laminates and further optimization is required. Improved understanding of the interrelation between the input prepreg material, the blank manufacturing process, the resulting blank quality, the stamp forming process and 
the final consolidation quality of the part is required for optimization of the process route in terms of the final consolidation quality and mechanical performance.

In case of partially preconsolidated blanks, void collapse and interlaminar bonding are two of the main consolidation mechanisms that have to occur during stamp forming in order

60

\section{Experimental work}

The experimental procedure for this work is illustrated in Fig. 2. Two types of C/PEEK prepregs with similar specifications, but very different cross-sections, are compared in order to investigate the influence of the initial state of the prepreg and highlight important prepreg characteristics. Blanks were manufactured from these prepregs through two automated laywith only local bonding provides blanks with a minimal degree of blank preconsolidation. An AFP process provides an intermediate degree of blank preconsolidation with continuous bonding. Additionally, press-consolidated blanks were produced as a reference of a con- 


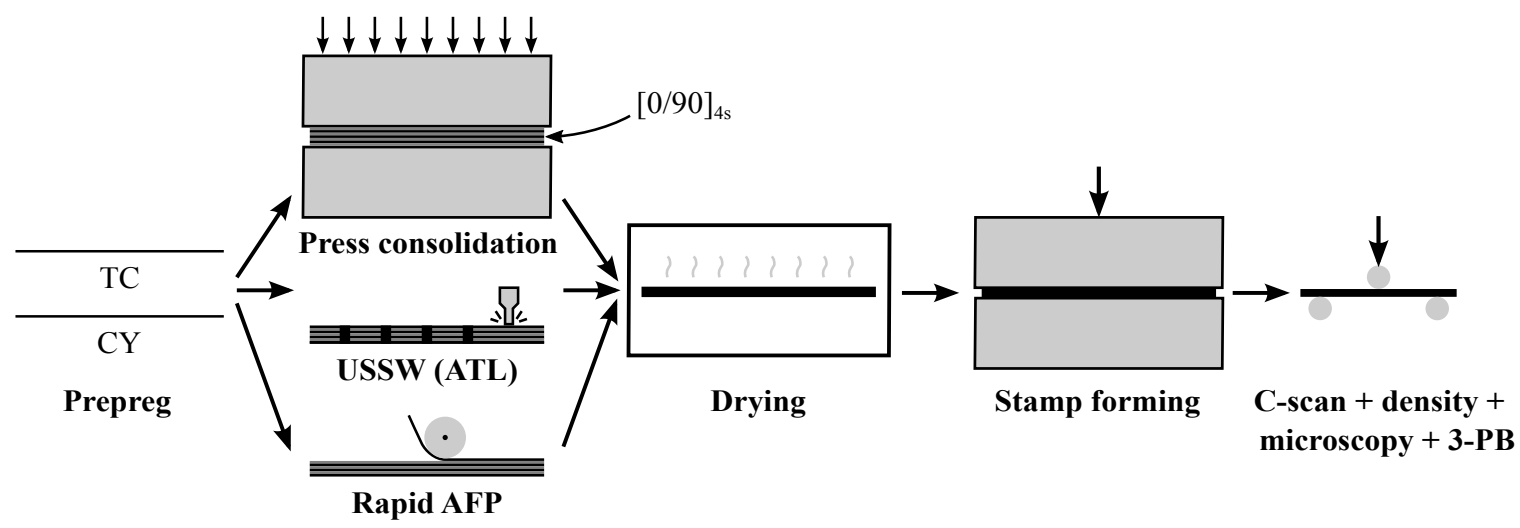

Figure 2: The steps in the experimental procedure.

ventional blank that is fully consolidated. The comparison between the three blank types will highlight the influence of blank preconsolidation level on final consolidation quality. A drying treatment was applied before forming to reduce deconsolidation effects by moisture [16]. The blanks were stamped into flat plates using various process settings in order to investigate the influence of the stamp forming process conditions on the final consolidation quality. The formed laminates were subjected to characterization of consolidation quality, with a focus on void content, and mechanical testing. The procedure is described in more detail in the following sections.

\subsection{Materials}

Two unidirectional C/PEEK prepreg tapes are compared in this work. Both are based on AS4 fibers and have a fiber volume fraction of approximately $59 \%$. The prepregs, TenCate Cetex ${ }^{\circledR}$ TC1200 [17] and Cytec APC-2 [18], are from this point referred to as TC and CY, respectively. Both prepregs have a melting temperature $T_{\mathrm{m}}$ of approximately $343{ }^{\circ} \mathrm{C}$ and a recommended processing temperature range of $370-400{ }^{\circ} \mathrm{C}$ and were available in 6 and $1 / 4$ inch width. Although their specifications are very similar, their cross-sections look very different, as shown in Fig. 3 (a) and (c). The CY prepreg has been around for a long time and is known for its non-uniform thickness and fiber/matrix distribution and a matrix-rich surface. It has intralaminar micro-voids, roughly $5-10 \%$, especially in areas with a high local fiber volume fraction. The TC prepreg is a more recent tape, which follows the trend 
(a)

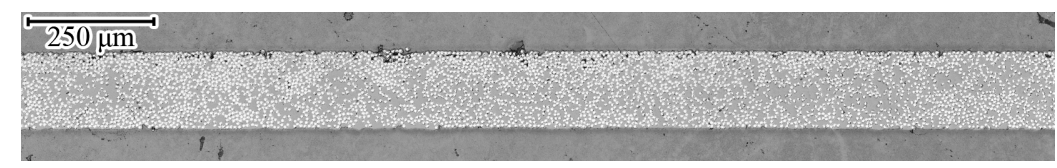

(b)

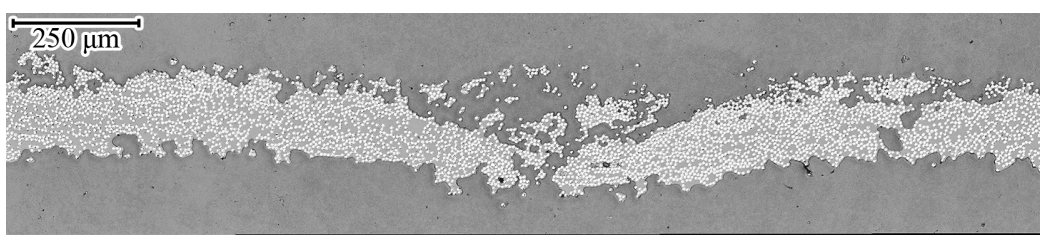

(c)

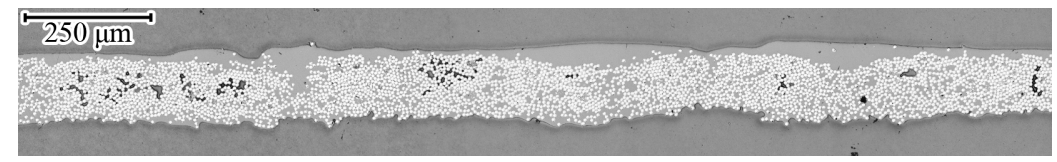

(d)

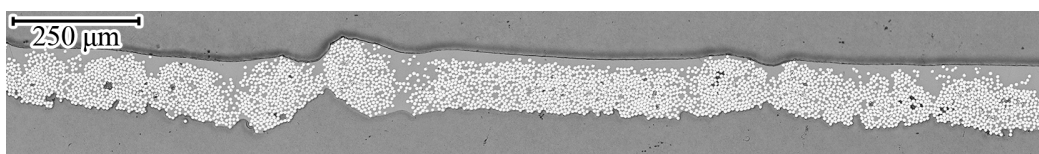

Figure 3: Cross-sectional micrographs of the (a) as-received and (b) deconsolidated TC prepreg and the (c) as-received and (d) deconsolidated CY prepreg.

of many modern prepregs by having a void-free cross-section, a smooth surface and a very uniform fiber/matrix distribution. There is no matrix-rich surface, which is surprising given that a matrix-rich surface is known to ease interlaminar bonding during rapid processing, like AFP [3, 14, 15]. The different cross-sections suggest that processing behavior during lay-up and stamping is likely to be different as well. A difference in processing behavior can also be seen in Fig. 3(b) and (d), which shows a cross-section of the as-received prepreg after heating it to $390{ }^{\circ} \mathrm{C}$ in a convection oven for 20 minutes with no external pressure applied. Void growth and decompaction of the fiber bed, so-called deconsolidation, is known to occur under these conditions due to the thermal expansion of dissolved moisture or the release of internal stresses [16]. As a result of the different processing behavior, the final consolidation quality and performance obtained after stamping may also be different.

\subsection{Blank manufacturing}

Blanks with a $[0 / 90]_{4 s}$ cross-ply lay-up of approximately $2.2 \mathrm{~mm}$ thick were manufactured from both prepregs using three different processes. The procedures for blank manufacturing 
are described below.

- USSW. $330 \times 150 \mathrm{~mm}^{2}$ blanks were prepared from 6 inch wide prepreg by ultrasonic spot welding (USSW). Each ply was locally bonded by spot welds with a diameter of approximately $10 \mathrm{~mm}$ on a $70 \times 70 \mathrm{~mm}^{2}$ grid, as is shown in Fig. 4. The spot welds provide sufficient blank integrity for handling, while also improving throughthickness heat transfer. USSW provides an extreme case where there is a complete lack of consolidation during lay-up and all consolidation has to take place during stamp forming. Although the spot welding was performed manually, it simulates the case of a blank produced by an ATL process, such as for example applied in the Fiberforge RELAY2000.

- AFP. A Coriolis Composites AFP robot with laser heating was used to produce $350 \times 350 \mathrm{~mm}^{2}$ laminates from a single $1 / 4$ inch tow at a rate of $200 \mathrm{~mm} / \mathrm{s}$ and a nip-point temperature of approximately $450{ }^{\circ} \mathrm{C}$ (measured by thermal camera). A compaction pressure of approximately 4 bar was applied by a silicone roller of $60 \mathrm{SH}$ hardness. $330 \times 150 \mathrm{~mm}^{2}$ blanks were cut from the laminates. These blanks have improved interlaminar bonding over the USSW blanks due to the continuous welding of the AFP process, but still have limited bonding and contain intralaminar voids, as the focus is on rapid lay-up, rather than in-situ consolidation.

- Press consolidation. $600 \times 600 \mathrm{~mm}^{2}$ laminate stacks were laid up manually from 6 inch prepreg. Each stack was placed between $1 \mathrm{~mm}$ stainless steel caul sheets coated with Marbocote 227 CEE release agent and consolidated in a 200 t Pinette P.E.I. press. A 20 minute dwell at $386{ }^{\circ} \mathrm{C}$ and 10 bar, and a cooling rate of $2.5{ }^{\circ} \mathrm{C} / \mathrm{min}$ were applied, resulting in a 2 hour consolidation cycle. $330 \times 150 \mathrm{~mm}^{2}$ blanks were cut from the laminates. This conventional blank manufacturing process serves as a reference for current practice in industry. 


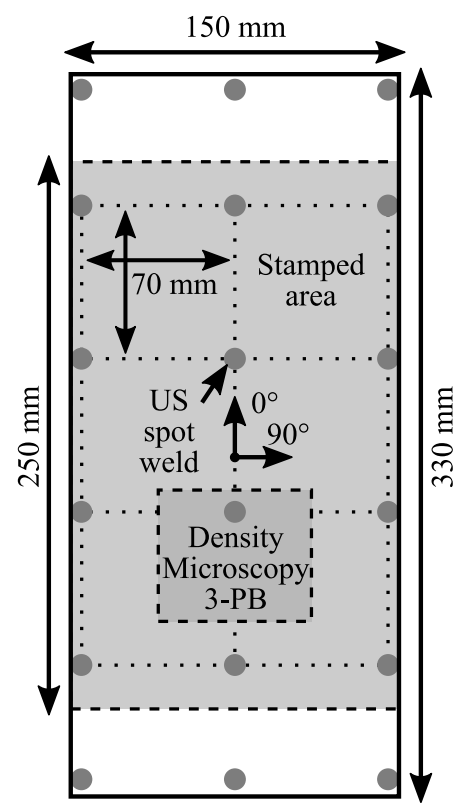

Figure 4: Lay-out of blanks with US spot weld locations and specimen location for analysis after stamping.

\subsection{Stamp forming}

All blanks were dried in a convection oven for 3 hours at $250{ }^{\circ} \mathrm{C}$ prior to stamp forming. Previous work by the authors [16] has shown that this reduces deconsolidation caused by expansion of dissolved moisture, which is undesired, as it introduces additional voids and delaminations that have to be eliminated again during stamping.

The blanks were then stamp formed using flat $250 \times 250 \mathrm{~mm}^{2}$ aluminum tooling in a 200 t Pinette P.E.I. press equipped with an infrared oven and automated transfer frame. In order to investigate the influence of the stamping process, both the blank temperature $T_{\text {blank }}$ and the consolidation pressure $P_{\text {cons }}$ were varied, as these parameters are known to have a significant effect on consolidation quality after stamping [19 21]. A $T_{\text {blank }}$ of $390{ }^{\circ} \mathrm{C}$ and a $P_{\text {cons }}$ of 20 bar were applied as baseline, which is usually sufficient for press-consolidated blanks [17]. The consolidation pressure was applied for 60 seconds while the laminate cooled down to the tooling temperature of $250{ }^{\circ} \mathrm{C}$. The tooling temperature and consolidation time were kept constant during all experiments. The USSW and AFP blanks, which were, as mentioned earlier, not fully consolidated, might require a $T_{\text {blank }}$ and higher $P_{\text {cons }}$ in order to achieve sufficient consolidation during stamping. Therefore, an increased $T_{\text {blank }}$ of $420{ }^{\circ} \mathrm{C}$ 
Table 1: Stamp forming parameters. A tool temperature of $250{ }^{\circ} \mathrm{C}$ and a consolidation time of $60 \mathrm{~s}$ were applied during all experiments.

\begin{tabular}{l|cc}
\hline Blank type & $\begin{array}{c}\mathbf{T}_{\text {blank }}\left(\mathbf{T}_{\text {panel }}, \mathbf{t}_{\text {heat }}\right) \\
{ }^{\circ} \mathrm{C}\left({ }^{\circ} \mathrm{C}, \mathrm{s}\right)\end{array}$ & $\begin{array}{c}\mathbf{P}_{\text {cons }} \\
\text { bar }\end{array}$ \\
\hline Press & $390(450,250)$ & 20 \\
Press & $420(485,250)$ & 100 \\
USSW & $390(450,300)$ & 20 \\
USSW & $420(485,300)$ & 100 \\
AFP & $390(450,250)$ & 20 \\
AFP & $420(485,250)$ & 20 \\
AFP & $390(450,250)$ & 100 \\
AFP & $420(485,250)$ & 100 \\
\hline
\end{tabular}

and an increased $P_{\text {cons }}$ of 100 bar were also applied. The heating times $t_{\text {heat }}$ and IR-heater panel temperatures $T_{\text {panel }}$ that were required to reach the desired blank temperatures were determined during heating trials, as described in Appendix A. The process settings are summarized in Tbl. 1. Cycle times of 5-6 minutes are achieved thanks to the use of IR blank heating and a isothermal tooling, which is much faster than the 2 hour press consolidation cycle used to preconsolidate blanks.

\subsection{Consolidation quality}

The stamp formed blanks were trimmed to their stamped area of $250 \times 150 \mathrm{~mm}^{2}$ and their consolidation quality was evaluated, where the focus was on void content and interlaminar bonding.

Ultrasonic C-scans were performed using a Sonatest RapidScan2 at a frequency of $5 \mathrm{Mhz}$. The scans give a qualitative picture of the global consolidation quality, as areas with porosity or poor interlaminar bonding will cause damping of the signal, which is visible as dark areas in the scans. For further inspection, specimens were cut from the blanks for cross-sectional micrographs and density measurements. The location of the specimens is specified in Fig. 4. Three $60 \times 15 \mathrm{~mm}^{2}$ specimens were used for density measurements in ethanol according 
to ASTM D792. The measured density $\rho$ can be used to estimate the void content $v_{\mathrm{v}}$ when compared to a reference density $\rho_{0}$ of a void-free laminate according to:

$$
v_{\mathrm{v}}=1-\frac{\rho}{\rho_{0}} \times 100 \%
$$

In this work, the density of the press-consolidated laminates was used as reference.

\subsection{Mechanical performance}

In order to evaluate the mechanical performance of the stamped laminates, flexural performance was determined based on 3-point bending tests according to ASTM D 7264 on an Instron 5900 UTM. Flexural performance is known to be sensitive to voids [22]. The test introduces the highest stresses near the top and bottom surface of the specimen. These areas are also likely to contain most voids, as the cooling rates during stamping are highest near the surface, which limits the time available for consolidation here. The specimens that were used for the density measurements were also used for flexural testing. The $0^{\circ}$ fiber direction was along the length of the specimens. A support span of $44 \mathrm{~mm}$ was applied, resulting in a span-to-thickness ratio of approximately 1:20. The load was applied by a loading nose with a radius of $6.4 \mathrm{~mm}$ at a rate of $1 \mathrm{~mm} / \mathrm{min}$ and measured by a $10 \mathrm{kN}$ force cell. The deflection of the specimen was measured at the center using a deflectometer. The apparent flexural strength $\sigma_{\max }$, which is based on a homogenized elastic beam, is calculated according to:

$$
\sigma_{\max }=\frac{3 F_{\max } L}{2 b h^{3}}
$$

Here, $F_{\max }$ is the maximum force, $L$ the support span and $b$ and $h$ are the width and thickness of the specimen, respectively.

\section{Results}

\subsection{Consolidation quality}

\subsection{1. $C$-scan}

Figure 5 shows amplitude plots of the back-wall echo for both the TC and CY blanks after stamp forming. The press-consolidated blanks show C-scans identical to their unstamped 
reference blanks with uniform consolidation and no influence of the stamping parameters $T_{\text {blank }}$ and $P_{\text {cons. }}$. The USSW blanks show very poor consolidation quality in a distinct, highly symmetric pattern at a $T_{\text {blank }}$ of $390{ }^{\circ} \mathrm{C}$ and $P_{\text {cons }}$ of 20 bar. Large areas with no signal feedback indicate poor interlaminar bonding and porosity between the plies, possibly due to a lack of pressure. The TC blank showed rough areas on the surface of the blank corresponding to the dark areas in the C-scan, while large blisters from entrapped air pockets were observed on the surface of the CY blank. The consolidation quality of the USSW blanks improves significantly for the increased $T_{\text {blank }}$ and $P_{\text {cons }}$, although some small defect areas remain. The C-scans of the TC AFP blanks indicate that some porosity is present after stamping at 20 bar, but that consolidation quality improves when increasing $P_{\text {cons }}$ to 100 bar. Increasing $T_{\text {blank }}$ did not affect consolidation quality much. The same trend is not visible for the CY AFP blanks, where the C-scans look similar for all process settings and good consolidation already is achieved at $390{ }^{\circ} \mathrm{C} / 20$ bar.

\subsubsection{Microscopy}

Figures 6 and 7 show a selection of cross-sectional micrographs of the three blank types for the TC and CY prepreg, respectively. The press-consolidated blanks are void-free for both prepregs both before (Fig. 6 (a) and 7 (a)) and after stamping (Fig. 6 (b) and 7 (b)). The cross-section of the TC USSW blank stamped at a $T_{\text {blank }}$ of $420{ }^{\circ} \mathrm{C}$ and $P_{\text {cons }}$ from a region that also showed good consolidation in the C-scan and therefore may not be representative for the entire blank. The TC USSW blank stamped at $390{ }^{\circ} \mathrm{C} / 20$ bar showed poor interlaminar bonding, while an additional cross-section taken from a region of the blank that showed low damping in the C-scan was void-free. Similar results were obtained for the CY USSW blanks, although some intralaminar micro-voids could still be observed in areas with high local fiber density (Fig. 7 (c)). The TC AFP blank (Fig. 6 (d)) shows incomplete interlaminar bonding and intralaminar voids prior to stamping due to the focus on high lay-up rates, rather than in-situ consolidation. Prior to stamping, the TC AFP blanks showed significant deconsolidation during heating in the IR oven (Fig. 6 (e)). Plies 


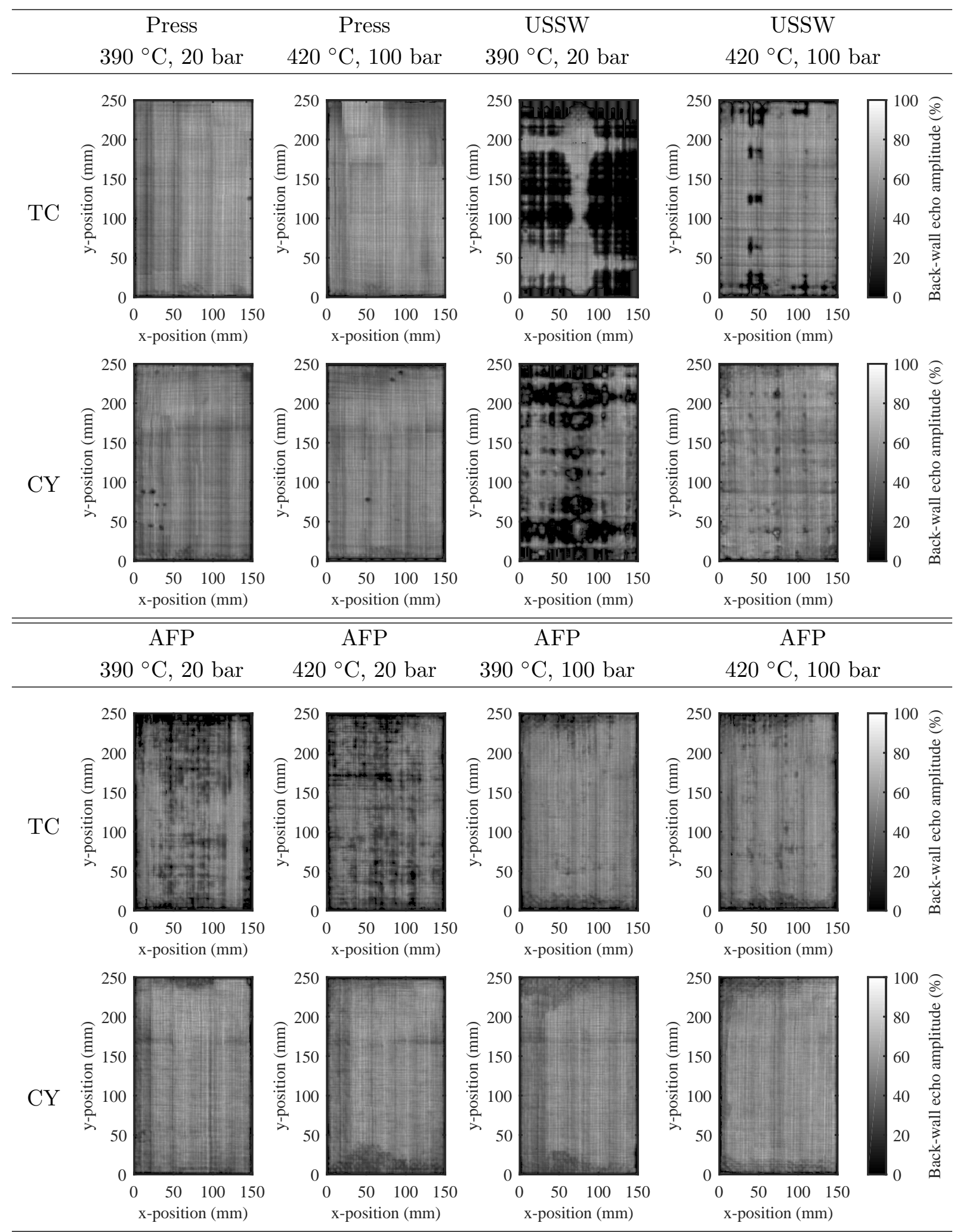

Figure 5: C-scans of the blanks after stamping. Shown parameters are $T_{\text {blank }}$ and $P_{\text {cons }}$. 

are obtained for press-consolidated blanks. A void content of $1 \%$ is achieved for the USSW blank. However, note that the specimens were taken from a region that also showed good 


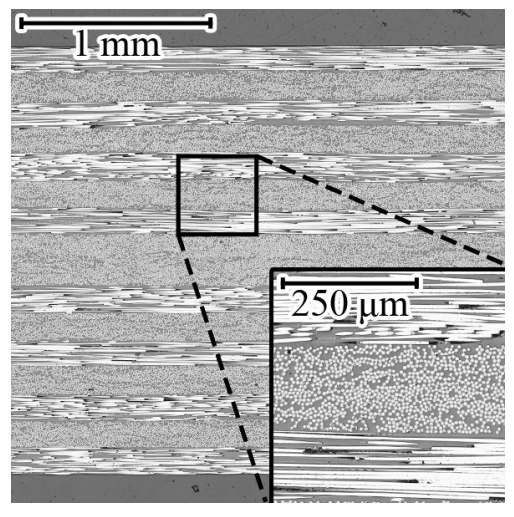

(a) TC Press, unstamped

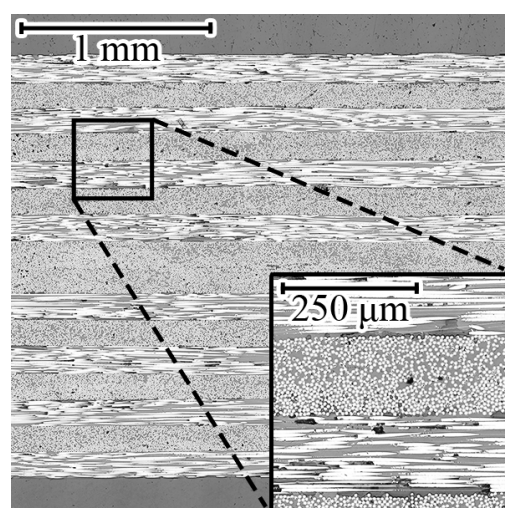

(d) TC AFP, unstamped

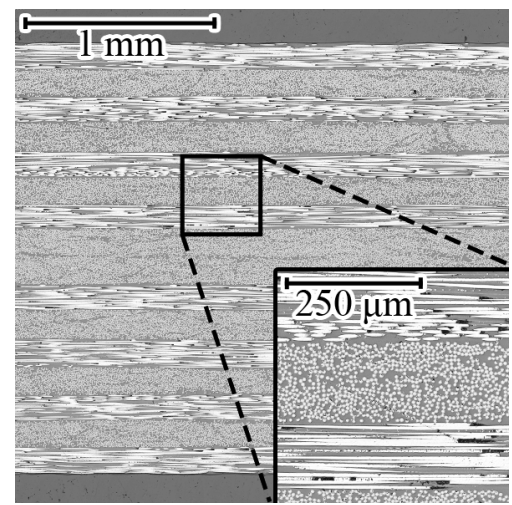

(b) TC Press, $390{ }^{\circ} \mathrm{C} / 20$ bar

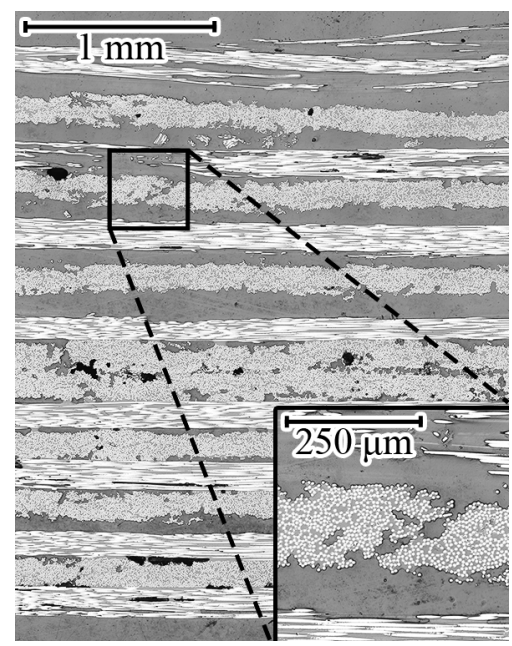

(e) TC AFP, deconsolidated

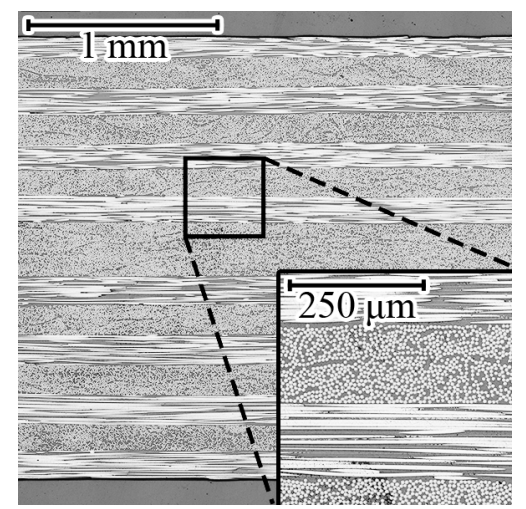

(c) TC USSW, $420{ }^{\circ} \mathrm{C} / 100$ bar

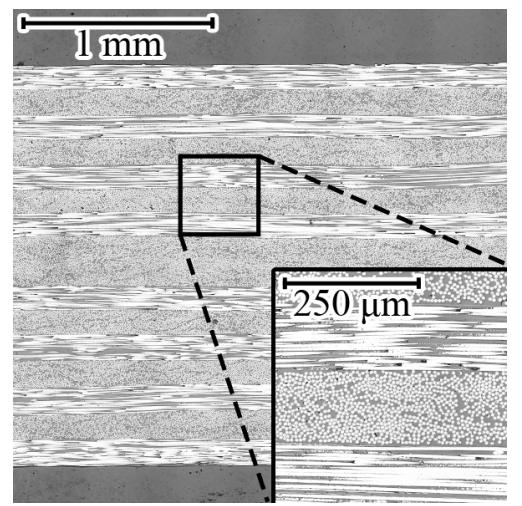

(f) $\mathrm{TC}$ AFP, $420{ }^{\circ} \mathrm{C} / 100$ bar

Figure 6: Cross-sectional micrographs of the TC blanks before and after stamping. Shown parameters are $T_{\text {blank }}$ and $P_{\text {cons }}$. Note: cross-section (c) may not be representative for entire blank. 


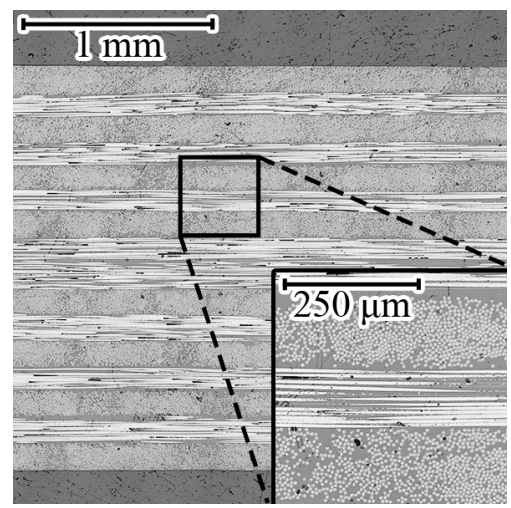

(a) CY Press, unstamped

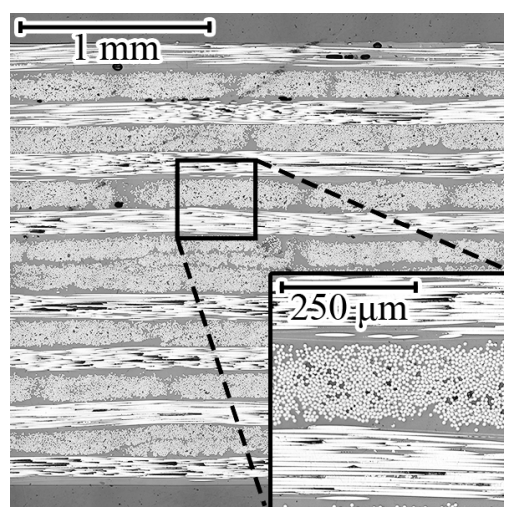

(d) CY AFP, unstamped

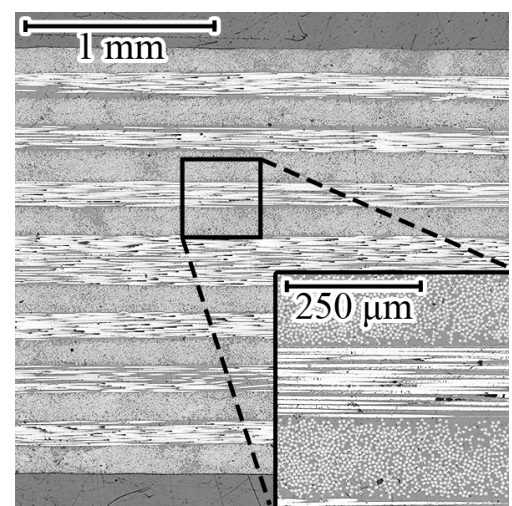

(b) CY Press, $390{ }^{\circ} \mathrm{C} / 20$ bar

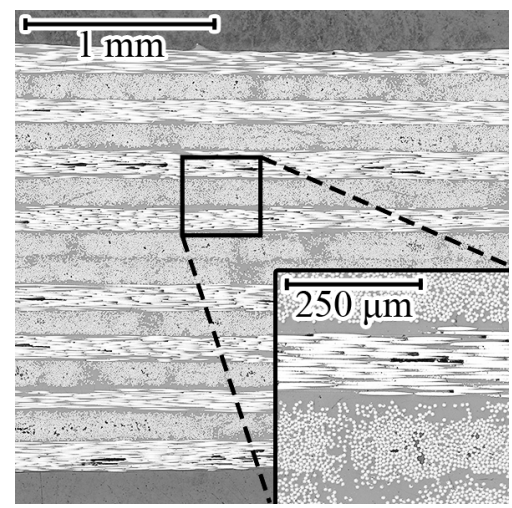

(e) CY AFP, deconsolidated

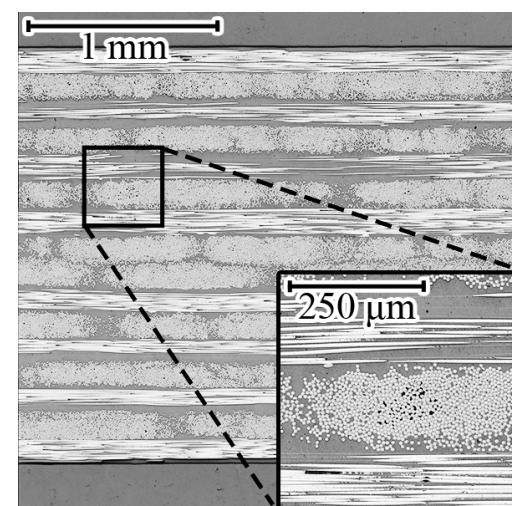

(c) CY USSW, $420{ }^{\circ} \mathrm{C} / 100$ bar

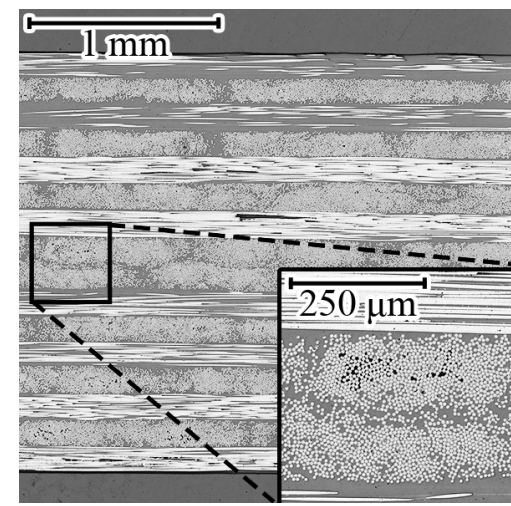

(f) $\mathrm{CY}$ AFP, $390{ }^{\circ} \mathrm{C} / 20$ bar

Figure 7: Cross-sectional micrographs of the CY blanks before and after stamping. Shown parameters are $T_{\text {blank }}$ and $P_{\text {cons }}$. Note: cross-section (c) may not be representative for entire blank. 


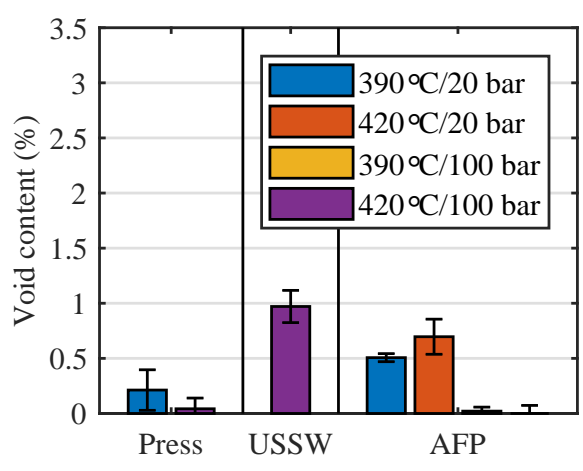

(a) TC

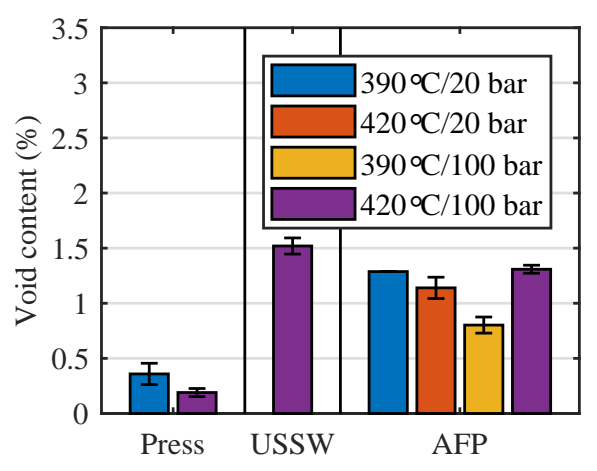

(b) $\mathrm{CY}$

Figure 8: Estimated void content of the (a) TC and (b) CY blanks after stamping based on density measurements. Void-free reference density TC $\rho_{0}=1580 \mathrm{~kg} / \mathrm{m}^{3}$ and CY $\rho_{0}=1580 \mathrm{~kg} / \mathrm{m}^{3}$. Legend shows $T_{\text {blank }}$ and $P_{\text {cons }}$. Note: the density measurement for the USSW blanks may not be representative for the entire blank.

consolidation in the C-scan and therefore may not be representative for the entire blank. The void content is slightly lower for the AFP blanks after stamping at $390{ }^{\circ} \mathrm{C} / 20$ bar, while increasing $P_{\text {cons }}$ to 100 bar reduces void content to almost zero. Similar results are found for the CY blanks, although no clear trend is visible for the AFP blanks and the void content seems to be higher for the USSW and AFP blanks compared to the TC blanks. This is not surprising, since the micrographs clearly showed that intralaminar voids were still present in these blanks after stamping. However, the density measurements seem to overestimate the void content of the CY blanks compared to the cross-sectional micrographs, possibly due to a small difference in fiber volume fraction compared to the reference blank. The void content of the unstamped AFP blanks was above $5 \%$ for both TC and CY, although this value is underestimated due to an overestimation of the density by filling of some of the voids with ethanol.

\subsection{Mechanical performance}

Figure 9 shows typical force-displacement curves obtained during flexural testing. All tested specimens showed a linearly increasing curve with a flexural modulus of approximately $70 \mathrm{GPa}$. Most specimens showed a minor load drop at approximately $80-90 \%$ of the 


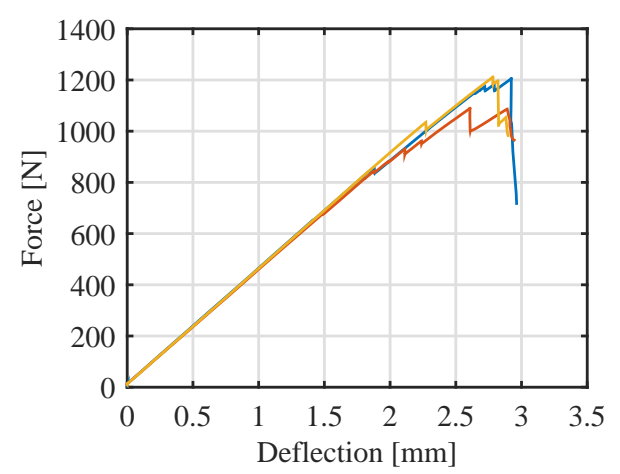

Figure 9: Force-deflection curves for the three specimens from the TC AFP blank stamped at a $T_{\text {blank }}$ of $420{ }^{\circ} \mathrm{C}$ and $P_{\text {cons }}$ of 100 bar.

ultimate flexural stress. Failure occurred by buckling and compressive failure of the top plies close to the loading nose.

The apparent flexural strength of the specimens is shown in Figs. 10 (a) and (b) for the TC and CY blanks, respectively. Again, due to the highly non-uniform consolidation found in the C-scans, the USSW blanks stamped at $390{ }^{\circ} \mathrm{C} / 20$ bar were not included in flexural testing. All stamped specimens show an apparent flexural strength of approximately $1100 \mathrm{MPa}$. For the TC blanks there seems to be a slightly increasing trend for higher $T_{\text {blank }}$ and $P_{\text {cons }}$, corresponding with the improved consolidation quality observed in Section 3.1 . The CY blanks show similar performance, but no obvious trend for the AFP blanks, which was also observed for the consolidation quality. The intralaminar micro-voids that were observed in the CY USSW and AFP blanks do not seem to affect the flexural performance. The similar strength of the stamped USSW blanks is impressive, given that the plies were completely unbonded prior to stamping. However, note that the flexural specimens were taken from a region that also showed good consolidation in the C-scans and therefore may not be representative for the entire blank. A drop in strength of about $10 \%$ is found for all stamped blanks compared to the press-consolidated reference laminates. Additional DSC analyses showed no difference in bulk crystallinity for all stamped blanks and the press-consolidated reference that could explain this strength drop. Further explanation of the strength drop was considered outside the scope of this work, but may require careful 


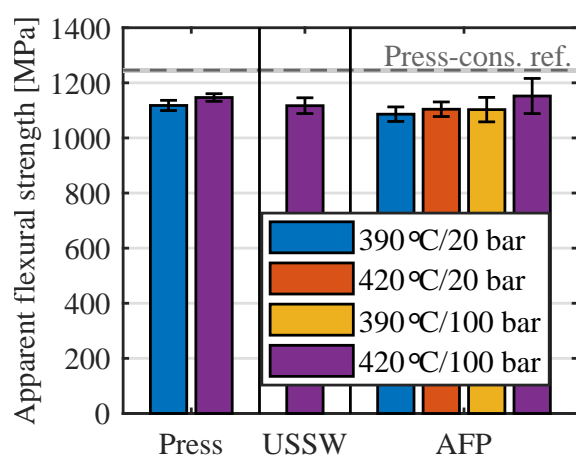

(a) $\mathrm{TC}$

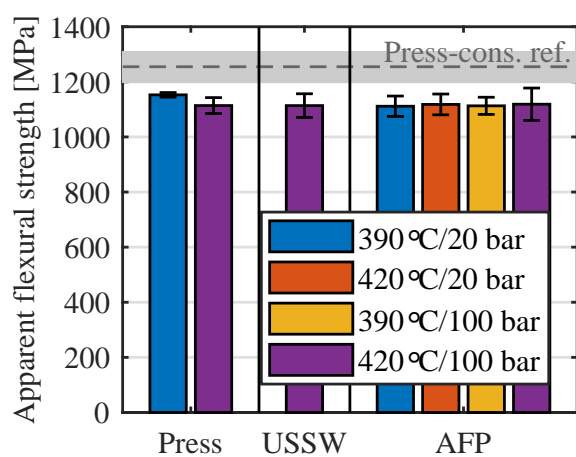

(b) $\mathrm{CY}$

Figure 10: Apparent flexural strength of the (a) TC and (b) CY blanks after stamping compared to a press-consolidated TC reference laminate. The legend shows $T_{\text {blank }}$ and $P_{\text {cons }}$. Note: the apparent flexural strength for the USSW blanks may not be representative for the entire blank.

investigation of the obtained microstructure, rather than bulk properties.

\section{Discussion} to a mismatch in blank thickness and tooling gap in combination with a lack of material 


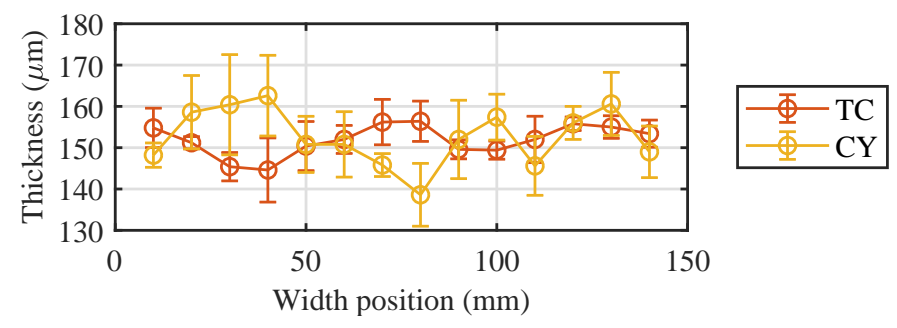

Figure 11: Prepreg thickness profile across the width (perpendicular to fiber direction). Measured by micrometer with $3 \mathrm{~mm}$ radius tip. Average and standard deviation of five equidistant measurements over a distance of $10 \mathrm{~m}$ along the length of the prepreg (fiber direction).

flow. While thickness variations are usually eliminated during blank manufacturing by a long press consolidation cycle, they may remain present during rapid automated lay-up.

In order to further investigate this hypothesis, thickness measurements were performed on the used prepreg. The thickness profile across the width of the prepreg was measured by a micrometer with $3 \mathrm{~mm}$ radius tip. Figure 11 shows the average thickness profile of five equidistant measurements over a distance of $10 \mathrm{~m}$ along the length of the prepreg (fiber direction). The results show profiles which deviate sometimes more then $5 \%$ from the average of $150 \mu \mathrm{m}$, but are relatively constant along the length. The CY prepreg shows a larger standard deviation due to the strong local variation of matrix content on the surface of the prepreg.

The thickness of the USSW blanks prior to stamping was estimated based on the prepreg thickness profiles, assuming that the thickness profile is constant along the length of the prepreg, and the stacking pattern, as is shown in Fig. 12. The resulting thickness distributions are shown and compared to the C-scans of the stamped blanks in Fig. 13. The thickness distributions show highly symmetric patterns similar to the C-scans due to the mirroring of the plies at the mid-plane, as well as the somewhat symmetric thickness profile of the prepreg. The well and poorly consolidated regions in the C-scans seem to correspond with the thickest and thinnest regions, respectively.

The previous observation supports the hypothesis that intimate contact development takes place on a more global scale by the elimination of blank thickness variations which originate from prepreg thickness variations, rather than local intimate contact development. 


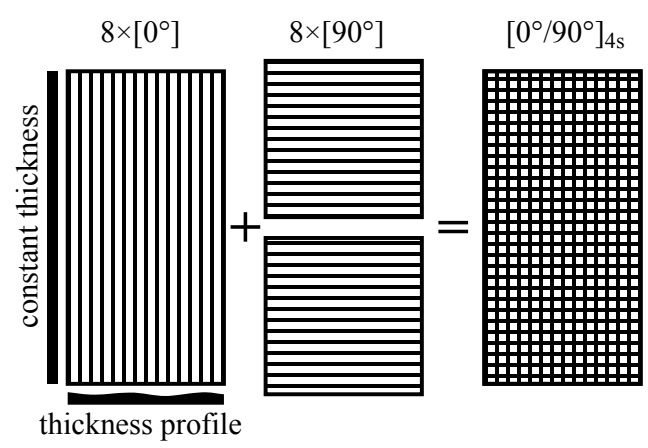

Figure 12: Blank thickness estimation based on prepreg thickness profile and stacking pattern.

In case of a USSW blank, the small thickness variations in the prepreg are added up when stacking multiple plies on top of each other, especially when the stacking pattern is very regular. At a low pressure of 20 bar there is not enough time for material redistribution by flow and achieving uniform consolidation. Instead, most pressure is carried by the thickest regions and the thin regions experience insufficient pressure for interlaminar bonding and void elimination. Increasing the pressure increases the generated flow, hence consolidation quality of the USSW blanks improved significantly by increasing the pressure to 100 bar. Similar thickness variations may be expected in AFP blanks. Since AFP tows are generally slit from wide prepreg rolls, the thickness profile of the prepreg persists as the tow-to-tow thickness variation. However, the AFP blanks in this work were prepared using a single $1 / 4$ inch tow, hence thickness variations due to tow-to-tow differences were not present within a blank, assuming that the thickness variation along the length of the prepreg is negligible. Additionally, thickness variations may arise from gaps and overlaps that appear due to tow width variation, lay-up tolerances or tape widening.

\subsection{Other prepreg characteristics}

Besides the previously discussed thickness variations, other characteristics of the prepreg play an important role in the consolidation behavior of the blanks. Firstly, the fiber/matrix distribution plays an important role in interlaminar bonding. This is well known and is confirmed by the results. The non-uniform fiber/matrix distribution and matrix-rich surface of the CY prepreg seem to facilitate interlaminar bonding both during AFP and stamp 


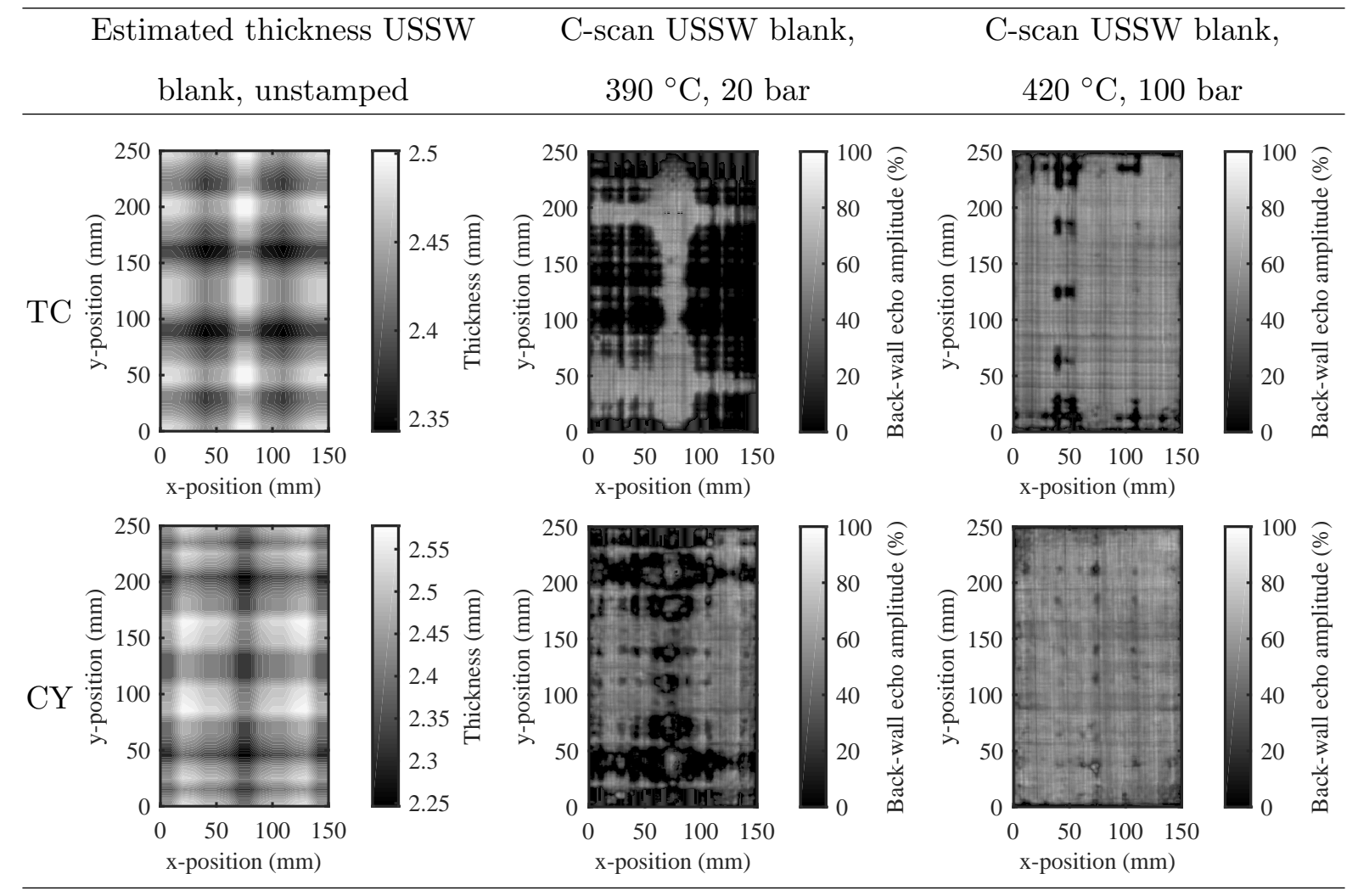

Figure 13: Estimated blank thickness distribution of the USSW blanks before stamping and C-scans after stamping. Shown parameters are $T_{\text {blank }}$ and $P_{\text {cons }}$.

forming. This is supported by the reasonably good interlaminar bonding in the crosssectional micrograph of the CY AFP blank (Fig. 7(d)) and the full interlaminar bonding that was already achieved after stamping at low pressure and blank temperature (Figs. 7 (f) and 5). In fact, interlaminar bonding already improved while heating the CY USSW and AFP blanks to its processing temperature without any external pressure applied (Fig. 7 (e)). Achieving good interlaminar bonding seemed more challenging for the TC prepreg with a more uniform fiber/matrix distribution and lack of matrix-rich surface, as the Cscans and micrographs indicated incomplete interlaminar bonding at low pressure and blank temperature (Figs. 6 (f) and 5). Since it is well known that interlaminar bonding benefits from a matrix-rich surface, it is surprising that many modern prepregs tend to have a lack of matrix on the surface.

Secondly, the non-uniform fiber/matrix distribution of the CY prepreg is accompanied 
by the presence of micro-voids in the prepreg (Fig. 3 (c)). These were not present in the TC prepreg (Fig. 3 (a)). The larger initial void content of the CY prepreg also leads to a higher final void content, as these micro-voids are not completely eliminated during both blank manufacturing and stamp forming (Fig. 7(f)). The local dense fiber packing most likely hinders two flow of matrix that is required to collapse the voids. Nevertheless, it is worth mentioning that the void content was low enough to not significantly affect flexural performance, although other mechanical properties may be more sensitive.

Finally, the two prepregs showed a striking difference in deconsolidation behavior of the as-received prepreg (Figs. 3 (b,d)). This behavior seems to persist in the AFP blanks (Figs. 6 (e) and 7 (d)). In both cases, the TC prepreg showed more deconsolidation than the CY prepreg, possibly due to a combination of frozen-in fiber stresses in the prepreg and a lack of interlaminar bonding in the TC AFP blanks [16]. The CY prepreg and AFP blank showed no significant deconsolidation. Despite the deconsolidation observed for the TC AFP blanks, the results show that the additional voids and delaminations formed by deconsolidation can be eliminated again during stamp forming. However, the combination of deconsolidation and the absence of a matrix-rich prepreg surface could explain why the TC AFP blanks require more pressure for good consolidation than the CY AFP blanks. Moreover, it is expected that a loss of blank integrity due to deconsolidation will affect forming behavior and lead to forming defects during stamping of more complex geometries.

Based on the discussion of the four important prepreg characteristics, a prepreg that enables good consolidation during the processing route has a very uniform thickness, matrix rich surface, is void-free and does not deconsolidate significantly.

\subsection{Influence of blank preconsolidation state}

The three blank manufacturing processes investigated in this work resulted in various degrees of preconsolidation ranging from almost none, with only local bonding between the plies, to fully preconsolidated. While a significant influence of the blank preconsolidation state, in particular degree of interlaminar bonding, on the final consolidation quality was expected, the difference between the three blank types was only modest. However, the 
consolidation window during stamp forming at low blank temperature and consolidation pressure is clearly too short to fully consolidate the USSW blanks. Unlike initially expected, this is not due to the initial lack of interlaminar bonding in the blank, but can mainly be attributed to the thickness variations in the prepreg, as discussed in Section 4.1. Hence, the ability to consolidate a blank during stamp forming seems to be mainly determined by the thickness variations and the properties that govern the flow that is required to redistribute the material, such as viscosity, temperature and pressure.

\subsection{Influence of stamp forming parameters}

The influence of the stamp forming parameters was confirmed by the fact that increasing the blank temperature and stamping pressure significantly improved the consolidation quality of the USSW blanks to a level that is close to the other blank types. Increasing the consolidation pressure for the AFP blanks also resulted in improved consolidation quality, while the influence of an increased the blank temperature was negligible. Considering this, it may be advisable to stick to lower blank temperatures (within the recommended processing range) in order to reduce heating time and limit potential polymer degradation. Additionally, an increased tool temperature will reduce the cooling rate and increase the consolidation window, although this was not tested in this work. Non-isothermal tooling, for example using induction heating and water cooling, could be helpful in this case, as it allows for high heating and cooling rates in order to maintain a short cycle time.

\subsection{Blank manufacturing by rapid automated lay-up}

Despite the large variation in the initial blank quality, similar consolidation quality was achieved after stamp forming for all blank types. A void content of less than $1 \%$ was obtained and flexural performance was identical for all blank types. This confirms that high quality laminates can be produced by stamp forming blanks manufactured by rapid automated lay-up.

Of the two tested automated lay-up technologies, AFP seems most promising, as the consolidation quality and mechanical performance are similar to press-consolidated blanks 
after stamp forming, even at low blank temperature and consolidation quality. However, this study has only looked at stamp forming of flat laminates manufactured from a single tow. The influence of tow-to-tow thickness variations was not investigated, but could lead to similar problems as with the USSW blanks.

A key challenge in the consolidation of automated lay-up blanks is the elimination of the mismatch in blank thickness and tool cavity. This challenge further increases when parts become more complex. The ability to ensure sufficient consolidation pressure on the entire part during forming depends on the compaction and flow behavior of the used prepreg. Further research on this is required to get more insight in the allowable thickness variations and required process parameters. Additionally, using non-rigid tooling would allow the tooling to accommodate for small variations in blank thickness and provide a more uniform pressure distribution. This would mean that less material flow is required and lower consolidation pressures would be possible. Further research should cover more complex geometries, which include forming and tailored lay-ups. The deconsolidation of AFP blanks deserves additional attention, as the reduced blank integrity may affect the forming behavior when forming more complex parts, as was discussed in Section 4.2. Similar issues may be expected when forming USSW blanks, since the local spot welding provides very little blank integrity. Another drawback of the USSW blanks is their increased heating time (by $20 \%$ in this work) due to the poor through-thickness thermal conductivity. This increases both cycle time and the risk of polymer degradation.

\section{Conclusions and Recommendations}

The combination of rapid automated lay-up and stamp forming was investigated as a potential promising process route for the manufacturing of load carrying tailored components. A main common characteristic of the two processes is the limited amount of time for consolidation. This means that thorough understanding of interrelation between input prepreg material, preconsolidation process, blank quality, stamp forming process and final consolidation quality is necessary to bring this process route forward. 
An experimental study was performed where two C/PEEK prepregs were processed into blanks by two rapid lay-up processes, AFP and USSW, and conventional press consolidation, providing various degrees of preconsolidation. These blanks were subsequently stamp formed at various process conditions. Characterization of consolidation quality of the stamped blanks was performed by C-scans, micrographs and density measurements. Mechanical performance was evaluated based on flexural tests.

The results confirm that void collapse and interlaminar bonding are the two main mechanisms that govern consolidation during stamp forming. However, interlaminar bonding was found to be dominated by the elimination of global thickness variations in the blank, rather than local intimate contact development between plies on a micro-scale. As a result, the blank thickness variations have a far more significant influence on the final consolidation quality than the initial degree of interlaminar bonding in a blank. When the redistribution of material by flow is insufficient during the short consolidation window during stamp forming, this results in a non-uniform pressure distribution and poorly consolidated regions. When the thickness variations are within acceptable limits, full interlaminar bonding can be achieved during stamp forming. An increased the consolidation pressure allowed for larger thickness variations, while the influence of an increased blank temperature was negligible. The results also confirm that the quality of the pepreg used to manufacture the blanks is crucial to the consolidation process. Four key prepreg characteristics were identified.

- Thickness distribution. Small prepreg thickness variations can cause significant blank thickness variations when stacked into a blank. For this reason, a uniform prepreg thickness can be considered as one of the most important prepreg characteristics. The thickness variations of the tested prepregs were of large influence on the consolidation of USSW blanks. Strong thickness variations were not observed in the tested AFP blanks due to the use of only a single tow, but may also occur in multi-tow AFP blanks due to tow-to-tow thickness variations.

- Fiber/matrix distribution. A matrix-rich surface of the prepreg was found to ease interlaminar bonding and material redistribution both during rapid lay-up and 
stamp forming, allowing faster consolidation and the use of lower pressures. Having a matrix-rich surface is therefore very beneficial for blanks produced by rapid automated lay-up.

- Intralaminar void content. Completely removing intralaminar voids that were initially present in the prepreg was not possible during both rapid lay-up and stamp forming under the studied conditions. Nevertheless, the final void content was low enough to not reduce the flexural performance, hence a low initial intralaminar void content seems acceptable.

- Deconsolidation behavior. The deconsolidation behavior of a prepreg was found to persist in blanks manufactured by rapid automated lay-up. Deconsolidation can be significant and highly prepreg specific. The combination of blank deconsolidation and the absence of a matrix-rich prepreg surface increases the time and pressure required for consolidation. Despite this, deconsolidation of AFP blanks was not found to have a major impact on final consolidation quality.

The current work has demonstrated that high quality laminates with a void content below $1 \%$ can be obtained after stamp forming, even when using blanks with a very low degree of preconsolidation. The flexural strength obtained after stamping of the rapid layup blanks considered was identical to that of stamped press-consolidated blanks. Results were most promising for lay-up by AFP. This gives confidence that the proposed process route has the potential for a step forward in the manufacturing of load carrying components. Further research should focus on the compaction and flow behavior of blanks in order to obtain more insight in the maximum allowable thickness variations and required stamping parameters. Furthermore, smart stacking of prepreg and the use of non-rigid tooling may improve consolidation quality after stamp forming by reducing blank thickness variations and by providing a more uniform pressure distribution, respectively. The current work should be extended to the consolidation of more complex parts, which include lay-up tailoring and single and double curvatures. The influence of a low blank integrity due to limited 
interlaminar bonding or deconsolidation on forming requires additional attention, as this may lead to unexpected forming behavior and forming defects. mid-plane and surface temperature when crossing the melt temperature due to deconsolidation, which reduces the through-thickness thermal conductivity by the formation of voids and delaminations.

This research was carried out under project number F11.4.15563 in the framework of the Partnership Program of the Materials innovation institute M2i (www.m2i.nl) and the Foundation of Fundamental Research on Matter (FOM) (www.fom.nl), which is part of the Netherlands Organisation for Scientific Research (www.nwo.nl). The authors gratefully acknowledge the financial and technical support from the industrial and academic members of the ThermoPlastic composites Research Center (TPRC), as well as the support funding from the Province of Overijssel for improving the regional knowledge position within the Technology Base Twente initiative.

\section{Appendix A. Blank heating behavior}

The heating times $t_{\text {heat }}$ in the IR oven that are required to achieve the desired blank temperatures $T_{\text {blank }}$ were determined during heating trials with laminates having thermocouples embedded at the mid-plane and underneath the surface plies. Figure A.1 shows results of the heating trials for the three blank types at a panel temperature $T_{\text {panel }}$ of $450{ }^{\circ} \mathrm{C}$ and a desired $T_{\text {blank }}$ of $390{ }^{\circ} \mathrm{C}$. The time required for the entire blank (i.e. both surface and mid-plane) to reach the desired temperature is dependent on the blank type. The AFP and press-consolidated blanks show very similar heating curves with very minimal temperature lag between surface and mid-plane, indicating good through-thickness thermal conductivity. The temperature lag is much larger for the USSW blanks due to the poor through-thickness thermal conductivity. This is because of the local bonding, which results in a lack of ply contact and insulating air layers between the plies. All blanks show a divergence of the

\section{Acknowledgments}




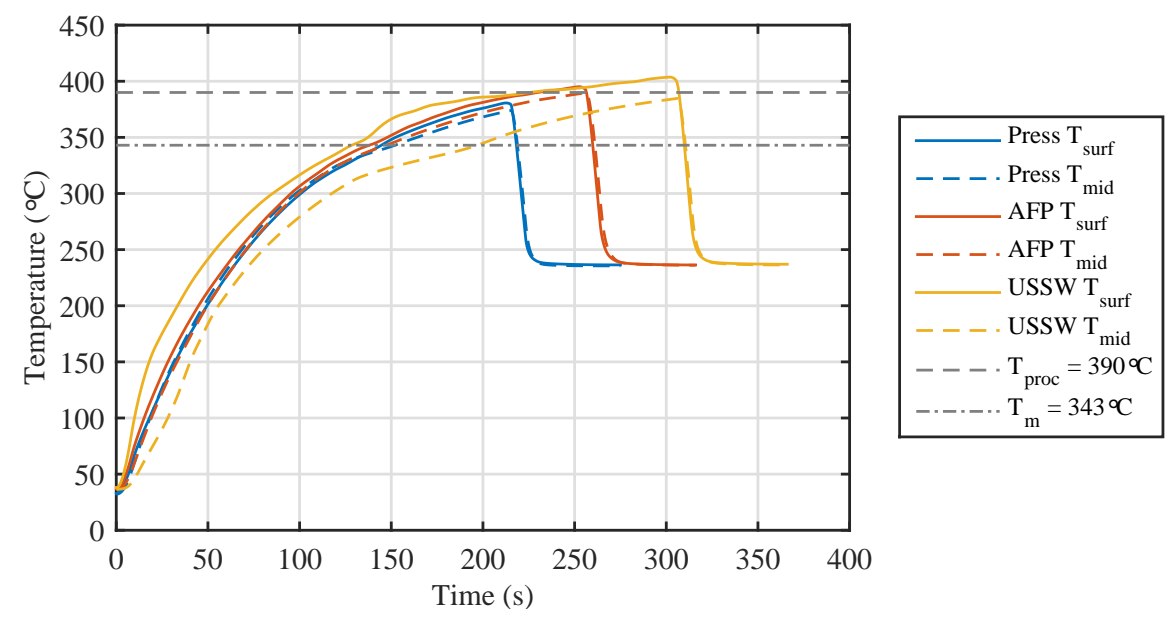

Figure A.1: Blank mid-plane and surface temperature measured by embedded thermocouples during heating trials at a heater panel temperature of $450{ }^{\circ} \mathrm{C}$. Note: tool temperature was $240{ }^{\circ} \mathrm{C}$ during heating trials.

Table A.1: IR heating parameters.

\begin{tabular}{l|ccc}
\hline Blank type & $\begin{array}{c}\mathbf{T}_{\text {blank }} \\
{ }^{\circ} \mathrm{C}\end{array}$ & $\begin{array}{c}\mathbf{T}_{\text {panel }} \\
{ }^{\circ} \mathrm{C}\end{array}$ & $\begin{array}{c}\mathbf{t}_{\text {heat }} \\
\mathrm{s}\end{array}$ \\
\hline Press, AFP & 390 & 450 & 250 \\
USSW & 390 & 450 & 300 \\
Press, AFP & 420 & 485 & 250 \\
USSW & 420 & 485 & 300 \\
\hline
\end{tabular}

The required heating parameters determined from the heating trials are shown in Tbl. A.1. A $t_{\text {heat }}$ of 250 seconds at a $T_{\text {panel }}$ of $450{ }^{\circ} \mathrm{C}$ were sufficient to reach a $T_{\text {blank }}$ of $390{ }^{\circ} \mathrm{C}$ for press-consolidated and AFP blanks, while the USSW blanks require 300 seconds. Note that, at this time, the surface ply of the USSW blanks already has been above the processing temperature for 75 seconds, which could potentially lead to polymer degradation. Increasing $T_{\text {panel }}$ to $485{ }^{\circ} \mathrm{C}$ was sufficient to reach a $T_{\text {blank }}$ of $420{ }^{\circ} \mathrm{C}$ in the same $t_{\text {heat }}$.

In Fig. A.1 all blanks show the same cooling curve with almost no through-thickness thermal gradient once they are stamped between the isothermal tooling. The blanks reach the tooling temperature of, in case of the heating trials, $240{ }^{\circ} \mathrm{C}$ in approximately 20 seconds. 


\section{References}

[1] M. A. Khan, R. Schledjewski, Influencing factors for an online consolidating thermoplastic tape placement process, in: 17th International Conference on Composite Materials, 2009.

[2] W. Grouve, Weld Strength of Laser-Assisted Tape-Placed Thermoplastic Composites, Ph.D. thesis, University of Twente (2012).

[3] M. Gruber, I. Lockwood, T. Dolan, Thermoplastic In Situ Placement Requires Better Impregnated Tapes and Tows, Proceedings of the 2012 SAMPE Conference.

[4] Z. Qureshi, T. Swait, R. Scaife, H. El-Dessouky, In situ consolidation of thermoplastic prepreg tape using automated tape placement technology: Potential and possibilities, Composites Part B: Engineering 66 (2014) 255-267. doi:10.1016/j.compositesb.2014.05.025

[5] C. Stokes-Griffin, P. Compston, The effect of processing temperature and placement rate on the short beam strength of carbon fibre-PEEK manufactured using a laser tape placement process, Composites Part A: Applied Science and Manufacturing 78 (2015) 274-283. doi:10.1016/j.compositesa.2015. 08.008 .

[6] A. Comer, D. Ray, W. Obande, D. Jones, J. Lyons, I. Rosca, R. O’ Higgins, M. McCarthy, Mechanical characterisation of carbon fibre-PEEK manufactured by laser-assisted automated-tape-placement and autoclave, Composites Part A: Applied Science and Manufacturing 69 (2015) 10-20. doi:10.1016/j. compositesa.2014.10.003.

[7] K. Yassin, M. Hojjati, Processing of thermoplastic matrix composites through automated fiber placement and tape laying methods: A review, Journal of Thermoplastic Composite Materials doi: 10.1177/0892705717738305.

[8] T. K. Slange, L. Warnet, W. J. B. Grouve, R. Akkerman, Influence of Preconsolidation on Consolidation Quality after Stamp Forming of C/PEEK Composites, in: ESAFORM 2016: Proceedings of the 19th International ESAFORM Conference on Material Forming, AIP Conference Proceedings, 2016. doi: $10.1063 / 1.4963578$

[9] T. K. Slange, L. L. Warnet, W. J. B. Grouve, R. Akkerman, Influence of Prepreg Characteristics on Stamp Consolidation, in: ESAFORM 2017: Proceedings of the 20th International ESAFORM Conference on Material Forming, AIP Conference Proceedings, 2017. doi:10.1063/1.5008021.

[10] T. Zenker, F. Bruckner, K. Drechsler, Experimental Analysis of Consolidation Processes for Preforms Manufactured by Thermoplastic Automated Fiber Placement, in: SAMPE Europe 2017, 2017.

[11] A. Schug, D. Rinker, R. Hinterhoelzl, K. Drechsler, Evaluating the potential of forming spot-welded layups out of fibre reinforced thermoplastic tape without previous consolidation, International Journal of Material Formingdoi:10.1007/s12289-018-1416-5.

[12] N. Bernet, V. Michaud, P.-E. Bourban, J.-A. Månson, Commingled yarn composites for rapid processing 
of complex shapes, Composites Part A: Applied Science and Manufacturing 32 (11) (2001) 1613-1626. doi:10.1016/S1359-835X(00)00180-9.

[13] D. Trudelboucher, B. Fisa, J. Denault, P. Gagnon, Experimental investigation of stamp forming of unconsolidated commingled E-glass/polypropylene fabrics, Composites Science and Technology 66 (34) (2006) 555-570. doi:10.1016/j.compscitech.2005.05.036

[14] M. A. Lamontia, M. B. Gruber, J. Tierney, J. W. Gillespie, B. J. Jensen, R. J. Cano, In Situ Thermoplastic ATP Needs Flat Tapes and Tows with Few Voids, in: 30th International SAMPE Europe Conference, Paris, 2009.

[15] R. Schledjewski, A. K. Schlarb, In-Situ Consolidation of Thermoplastic Tape Material Effects of Tape Quality on Resulting Part Properties, in: International SAMPE Symposium and Exhibition, Baltimore, 2007.

[16] T. K. Slange, L. L. Warnet, W. J. B. Grouve, R. Akkerman, Deconsolidation of C/PEEK blanks: on the role of prepreg, blank manufacturing method and conditioning, Composites Part A: Applied Science and Manufacturing.

[17] Ten Cate Advanced Composites, Product Data Sheet TenCate Cetex® TC1200 PEEK Resin System (2017).

[18] Cytec, Technical Data Sheet APC-2-PEEK Thermoplastic Polymer (2016).

[19] M. D. Wakeman, P. Blanchard, J.-A. E. Månson, Void Evolution During Stamp-Forming of Thermoplastic Composites, in: 15th International Conference on Composite Materials (ICCM-15), 2005.

[20] R. McCool, A. Murphy, R. Wilson, Z. Jiang, M. Price, J. Butterfield, P. Hornsby, Thermoforming carbon fibre-reinforced thermoplastic composites, Proceedings of the Institution of Mechanical Engineers, Part L: Journal of Materials: Design and Applications 226 (2012) 91-102. doi: $10.1177 / 1464420712437318$.

[21] H. Lessard, G. Lebrun, A. Benkaddour, X.-T. Pham, Influence of process parameters on the thermostamping of a [0/90]12 carbon/polyether ether ketone laminate, Composites Part A: Applied Science and Manufacturing 70 (2015) 59-68. doi:10.1016/j.compositesa.2014.12.009.

[22] X. Liu, F. Chen, A review of void formation and its effects on the mechanical performance of carbon fiber reinforced plastic, Engineering Transactions 64 (1) (2016) 33-51.

[23] Hexcel, HexTow ® AS4 Carbon Fiber Product Data Sheet (2018).

[24] P. Cebe, S.-D. Hong, Crystallization behaviour of poly(ether-ether-ketone), Polymer 27 (8) (1986) 1183-1192. doi:10.1016/0032-3861(86)90006-6 